\title{
Simple Superposition Approach for Dynamic Analysis of Piled Embedded Footings*
}

\author{
L.A. Padrón ${ }^{1}$, G. Mylonakis ${ }^{2}$, D.E. Beskos ${ }^{2}$ \\ ${ }^{1}$ University Institute SIANI, Universidad de Las Palmas de Gran Canaria, 35017, \\ Las Palmas de Gran Canaria, Spain \\ ${ }^{2}$ Department of Civil Engineering, University of Patras GR-26500, Patras, Greece
}

\begin{abstract}
The effectiveness and accuracy of the superposition method in assessing the dynamic stiffness and damping functions of embedded footings supported by vertical piles in homogeneous viscoelastic soil is addressed. To this end, the impedances of piled embedded footings are compared to those obtained by superposing the impedance functions of the corresponding pile groups and embedded footings treated separately, with the magnitude of the relative average differences being around $10-30 \%$. The results are presented in a set of dimensionless graphs and simple expressions that can be used to estimate the dynamic stiffness and damping of piled embedded footings provided that the impedance functions of its two components are known. This is precisely the reason why the superposition approach studied here is appealing, since such impedance functions for both embedded footings and pile groups are available for a wide range of cases. How to estimate the kinematic response functions of the system when those of the individual components are known is also discussed.

To address the problem, parametric analyses performed using a 3D frequencydomain elastodynamic BEM-FEM formulation, are presented for different pile-soil stiffness contrasts, embedment depths, pile-to-pile separations and excitation frequencies. Vertical, horizontal, rocking and cross-coupled horizontal-rocking impedance functions, together with translational and rotational kinematic response functions, are discussed. The results suggest that the superposition concept, in conjunction with a correction strategy as that presented herein, can be employed in geotechnical design. For kinematic effects, the response functions of the embedded footing are found to provide reasonable estimates of the system's behaviour.
\end{abstract}

Key words: Pile groups; Embedded foundations; Piled embedded footings; Dynamic stiffness; Kinematic response; Soil-structure interaction; Boundary element method.

\footnotetext{
* This is the peer-reviewed version of the following article: Padrón, Mylonakis, Beskos, Simple superposition approach for dynamic analysis of piled embedded footings, Int $\mathrm{J}$ for Numerical and Analytical Methods in Geomechanics 2012; 36:1523-1534, which has been published in final form at http://onlinelibrary.wiley.com/doi/10.1002/nag.1072/full. This article may be used for non-commercial purposes in accordance with Wiley Terms and Conditions for Self-Archiving.
} 


\section{Introduction}

A great amount of research has been conducted on the dynamic behaviour of pile groups and embedded footings in elastic or viscoelastic soil [Novak (1974), Blaney et al. (1976), Kaynia (1982), Dobry et al. (1982), Karabalis and Beskos (1986), Dobry and Gazetas (1988), Ahmad and Banerjee (1988), Mamoon and Banerjee (1990), Fan et al. (1991), Gazetas et al. (1991), Miura et al. (1994), Boulanger et al. (1999), Bentley and El Naggar (2000), Rollins et al. (2003), Ishihara and Cubrinovski (2004)]. Reviews have been contributed, among others, by Novak (1991), Pender (1993), Gazetas and Mylonakis (1998) and Mylonakis et al. (2006). A more complex foundation type is that of rigid embedded footings supported by piles under the base slab. Even though such foundations (to be referred hereafter to as "piled embedded footings") are widely used for supporting high-rise structures (e.g., Stewart and Stewart 1997), they have received limited research attention. To the extent of the authors' knowledge, only a few pieces of research have dealt with piled embedded footings - dealing exclusively with gravitational loads (Combarieu and Evrard 1979; Combarieu and Morbois 1982). This is in contrast to piled rafts (Cooke 1986; Poulos 2001; Reul and Randolph 2003) and soil-pile cap interaction problems (Butterfield and Banerjee 1971, Akinmusuru 1980; Chow and Teh 1991) for which a wider set of research results has been reported. This gap in knowledge provided the initial motivation for the herein reported work.

Given the two-component structure of these foundations (i.e., footing $\&$ piles), it is of interest to investigate whether their dynamic behaviour can be approximated by that of their parts analyzed separately and then superimposed. The idea is illustrated in Fig. 1, in which the system is conceptually decomposed into a pile group with a ground-raised pile cap (i.e., having no contact with the soil) at depth $\mathrm{D}$, and an embedded footing. The concept is only approximate - yet appealing, as it is intuitive and can incorporate a wealth of available data for both pile groups and embedded footings. Note that the embedment effect for the pile group, which is present in the footing, is not considered in order not to be counted twice. This superposition approach, although approximate, is acceptable from a material behavior viewpoint, since the response is linear. Also the development of gap or slippage between soil and pile cap (Fig. 1) is not defined, as contact effects are not considered.

The object of this work is twofold: $a$ ) to provide insight into the dynamic and seismic behaviour of piled embedded footings and $b$ ) to offer a practical way for estimating, with engineering accuracy, the impedance (i.e., springs and dashpots) and kinematic response functions for vertical $\mathrm{S}$ waves of this class of foundations, taking as the starting point the functions corresponding to footings and piles as separate systems, which are widely available from published material and specific computational tools.

To this end, a rigorous three-dimensional elastodynamic boundary element finite element numerical scheme, previously presented in two recent works (Padrón el al. 2007, 2008), was employed to explore the influence on the response of piled embedded footings of parameters such as pile-to-pile separation, embedment ratio, pile-soil stiffness ratio, number of piles and oscillation frequency. Relating the results of these analyses to the dynamic response of an identical pile group and an embedded footing treated separately, may allow a better understanding of the problem and also the possibility of establishing a simple approach for estimating the dynamic behaviour of the system based on information available in the literature. 
Firstly, the numerical model used to perform the analyses is outlined. Secondly, impedance functions of piled embedded footings are obtained and compared to those of an identical footing and pile group computed separately and then superimposed. Thirdly, simplified expressions that provide simple estimates of the impedance functions of the system based on the above superposition scheme are proposed. Finally, kinematic interaction factors for the whole system are computed and compared to those of pile groups and embedded footings.

\section{BEM-FEM coupling model}

The results presented in this paper have been obtained using a BEM-FEM scheme for the dynamic analysis of pile groups, where the Finite Element Method (FEM) is used to model the piles, and the Boundary Element Method (BEM) is used to model the soil and the footing.

The time-harmonic elastic behavior of piles, modeled through onedimensional elastic Euler-Bernoulli beams, can be described by an algebraic equation of the type

$$
\overline{\mathbf{K}} \mathbf{u}^{\mathrm{p}}+\mathbf{Q} \mathbf{q}^{\mathrm{s}}=\mathbf{F}^{\mathrm{ext}}
$$

where $\overline{\mathbf{K}}=\mathbf{K}-\omega^{2} \mathbf{M}$, with $\mathbf{K}$ and $\mathbf{M}$ being the stiffness and mass matrices of the pile, respectively. Here, $\omega$ is the circular excitation frequency, $\mathbf{u}^{p}$ is the vector of nodal translation and rotation amplitudes along the pile, $\mathbf{F}^{\text {ext }}$ is the vector of external forces over the pile, $\mathbf{q}^{\mathrm{s}}$ is the vector of tractions along the pile-soil interface, and $\mathbf{Q}$ is the tractions-to-equivalent nodal forces matrix. In the present study, Eq. (1) is discretized by one-dimensional three-node FEM elements on which displacements and rotations are considered at the extreme nodes.

The Boundary Element Method (Domínguez 1993, Beskos 1997) is used to model the soil, considered to be a three-dimensional, linear, zoned-homogeneous, isotropic, viscoelastic, unbounded region with complex-valued shear modulus $\mu$ of the type $\mu=\operatorname{Re}[\mu](1+2 i \xi)$, where $\xi$ is the damping coefficient. If the forces and tractions arising at the soil-pile interfaces are considered as body forces acting within a domain $\Omega$ with boundary $\Gamma$, the boundary integral equation for the time-harmonic elastodynamic state defined in such domain can be written as:

$$
\mathbf{c}^{k} \mathbf{u}^{k}+\int_{\Gamma} \mathbf{p}^{*} \mathbf{u} \mathrm{d} \Gamma=\int_{\Gamma} \mathbf{u}^{*} \mathbf{p} \mathrm{d} \Gamma+\sum_{j=1}^{n_{p}}\left[\int_{\Gamma_{p_{j}}} \mathbf{u}^{*} \mathbf{q}^{s_{j}} \mathrm{~d} \Gamma_{p_{j}}-\mathrm{Y}_{k}^{j} \mathbf{F}_{p_{j}}\right]
$$

where $\mathbf{c}^{k}$ is the local free term matrix at the collocation point, $\mathbf{u}$ and $\mathbf{p}$ are the displacement and traction vectors, $\mathbf{u}^{*}$ and $\mathbf{p}^{*}$ are the elastodynamic fundamental solution tensors representing the response of an unbounded region to a harmonic concentrated unit load, $n_{p}$ is the total number of piles in the domain, $\Gamma_{p_{j}}$ is the pile-soil interface along the pile $j$, and $\mathrm{Y}_{k}^{j}$ is a three-component vector representing the contribution of the axial force $\mathbf{F}_{p_{j}}$ at the tip of the $j^{\text {th }}$ pile. 
Once the footing-soil interface and a small extension of the surrounding free surface, has been discretized into quadratic elements of triangular and quadrilateral shape (Fig. 2), the boundary integral equation for the elastodynamic problem in the frequency domain can be written for all soil boundaries and pile nodes, leading to the condensed matrix equation

$$
\mathbf{C} \mathbf{u}^{\mathrm{p}}+\mathbf{H} \mathbf{u}^{\mathrm{s}}-\mathbf{G} \mathbf{p}^{\mathrm{s}}-\mathbf{G}^{\mathrm{p}} \mathbf{q}^{\mathrm{s}}+\mathbf{Y} \mathbf{F}_{\mathrm{p}}=\mathbf{0}
$$

where matrix $\mathbf{C}$ contains the free terms corresponding to the collocation process over the pile nodes, $\mathbf{H}$ and $\mathbf{G}$ are the coefficient matrices arising from the BEM and obtained by numerical integration over the boundary elements, $\mathbf{G}^{\mathrm{p}}$ and $\mathbf{Y}$ are the coefficient matrices obtained by integration over the pile elements, and $\mathbf{u}^{\mathrm{s}}$ and $\mathbf{p}^{\mathrm{s}}$ are the vectors of nodal displacements and tractions of boundary elements, respectively.

Imposing equilibrium and compatibility for fully bonded interfaces, Eqs. (1) and (3) can be coupled in an algebraic system of the type

$$
\left[\begin{array}{ccccc}
\mathbf{H} & -\mathbf{G} & -\mathbf{G}^{\mathrm{p}} & \mathbf{Y} & \mathbf{C} \\
\boldsymbol{\emptyset} & \boldsymbol{\emptyset} & \mathbf{Q} & \mathbf{I}^{\prime} & \overline{\mathbf{K}}
\end{array}\right]\left\{\begin{array}{l}
\mathbf{u}^{\mathrm{s}} \\
\mathbf{p}^{\mathrm{s}} \\
\mathbf{q}^{\mathrm{s}} \\
\mathbf{F}_{\mathrm{p}} \\
\mathbf{u}^{\mathrm{p}}
\end{array}\right\}=\mathbf{b}
$$

where $\mathbf{b}$ is the known vector computed by prescribing the boundary conditions. To determine the impedances, forced vibrations of the form $u(t)=u_{0} \exp [i \omega t]$ are imposed at point $\mathrm{A}$ in Fig. 1, where the reference system is defined, with the amplitude of motion, $\mathrm{u}_{\mathrm{o}}$, taken as unity. To obtain the kinematic interaction factors for vertically incident time-harmonic planar shear waves, the displacement and traction fields in the soil are considered as the superposition of incident and scattered fields, of which the former is known, thus allowing the statement of the equations in the scattered field with a known right hand vector. In this case, infinitely rigid massless footing and cap are considered.

For a detailed description of the model and validation of the numerical tool, the reader is referred to the works by Padrón et al. $(2007,2008)$.

\section{Numerical parametric analyses of piled embedded footings}

To investigate the dynamic behaviour of piled embedded square footings in viscoelastic soils, parametric analyses were carried out using the numerical method outlined above. The geometry of the model is depicted in Fig. 1, where $B$ and $D$ are foundation halfwidth and depth of embedment, $L$ and $d$ are length and sectional diameter of piles, respectively, and $s$ is the centre-to-centre spacing between adjacent piles. In the above, $B / s=n / 2$ with $n$ being the number of piles per side in square configuration. The dimensionless parameter sets considered as part of this investigation are $s / d=2$ and $5, D / B=1$ and 2, pile-soil stiffness contrast $E_{\mathrm{p}} / E_{\mathrm{s}}=1000$ and $100, n=2$ and 3 (leading to $B / s=1$ and 1.5 ) and dimensionless frequency $a_{\mathrm{o}}=$ 
$\omega d / c_{\mathrm{s}}$ from 0 to 1 in steps of 0.05 , with $\mathrm{c}_{\mathrm{s}}$ being the shear wave propagation velocity in the soil. Thus, a total of 336 parameter combinations are considered. The rest of properties, having generally second-order influence on dynamic response, are: mass density contrast between soil and pile $\rho_{\mathrm{s}} / \rho_{\mathrm{p}}=0.7$, pile slenderness ratio $L / d=15$, soil material damping coefficient $\xi=0.05$ and soil Poisson's ratio $v_{\mathrm{s}}=0.4$. Following Buckingham (1914), ten dimensionless system parameters were employed in total, as the number of independent, dimensional and dimensionless, variables is thirteen (i.e., $\left.L, d, B, D, s, E_{\mathrm{p}}, E_{\mathrm{s}}, \rho_{\mathrm{s}}, \rho_{\mathrm{p}}, \omega, v_{\mathrm{s}}, \xi, n\right)$ and the fundamental units three (i.e., Mass, Length, Time). Note that the pile length to diameter ratio $L / d$ is of secondary importance, as it exceeds the critical slenderness ratio beyond which the pile behaves essentially as an infinitely long foundation element (Randolph 1981). Note that shear wave velocity $c_{\mathrm{s}}$ is not an independent parameter, being merely a function of soil stiffness and density.

In this study, fully bonded contact conditions are considered in the vertical and horizontal interfaces between soil and footing, and soil and pile. The effect of separation between soil and the underside of the footing due to soil erosion and consolidation has been examined in a recent paper (Padrón et al. 2009).

A sensitivity analysis was performed to establish the characteristics of the optimal meshes leading to meshes of the kind shown in Fig. 2, in which the free surface discretization extends to eight times the embedment depth $D$ from the footing edge. It should be noticed that due to the symmetry of the problem, only a quarter of the geometry needs to be discretized. The total number of nodes and elements resulting from the above discretization is 3203 and 816 , respectively.

\section{Impedance functions}

The impedance functions, relating the forces (and moments) applied and the displacements (and rotations) observed at the top of the footing, are complex functions of the form $K=k+\mathrm{i} a_{0} c$, where $k$ and $c$ are the frequency-dependent dynamic stiffness and damping coefficients measured in units of $F \times L^{m}, m$ being -1 for the translational modes and +1 for the rotational; $i=\sqrt{ }-1$. Also note that the above representation of the impedance functions has the advantage that $\mathrm{k}$ and $\mathrm{c}$ coefficients have the same units Therefore, the superposition of the dynamic stiffness and damping functions of pile group and embedded footing to obtain the estimated impedance $K^{\mathrm{P}}$ of the system is performed as

$$
K^{\mathrm{P}}=\left(k_{\text {pile group }}+k_{\text {embedded footing }}\right)+\mathrm{i} a_{o}\left(c_{\text {pile group }}+c_{\text {embedded footing }}\right)
$$

The impedance functions can also be given in terms of its modulus and phase, defined as

$$
\bmod (K)=\sqrt{k^{2}+\left(a_{o} c\right)^{2}}
$$




$$
\operatorname{phase}(K)=\arctan \left(\frac{-k}{a_{o} c}\right)+\frac{\pi}{2}
$$

Using these definitions, the comparisons between the dynamic stiffness and damping functions of the piled embedded footing analyzed as a whole $\left(K^{\mathrm{W}}\right)$ and by superposition $\left(K^{\mathrm{P}}\right)$ will be presented in terms of dimensionless real-valued relative difference of moduli $(\chi)$ and phase in degrees $(\Delta \Theta)$, so that

$$
\bmod \left(K^{\mathrm{W}}\right)=\frac{\bmod \left(K^{\mathrm{P}}\right)}{1+\chi}
$$

and

$$
\operatorname{phase}\left(K^{\mathrm{W}}\right)=\operatorname{phase}\left(K^{\mathrm{P}}\right)-\Delta \Theta
$$

The values of $\chi$ and $\Delta \Theta$, for different cases, will be presented in the ensuing plots as functions of the dimensionless frequency $a_{\mathrm{o}}$, in such a way that the modulus and phase of the complex-valued dynamic stiffness functions of a complete pile groupembedded foundation system can be estimated with the help of Eqs $(8,9)$ and the corresponding plots. Evidently, the limits $\chi \rightarrow 0$ and $\Delta \Theta \rightarrow 0$ indicate insignificant interaction between embedded footing and pile group, whereas $\chi \rightarrow-1$ or $\infty$ and $\Delta \Theta \rightarrow \pm \pi$ suggest dominant interaction effects.

Comparisons between the impedance functions of $2 \times 2$ and $3 \times 3$ piled embedded footings computed as a whole $\left(K^{\mathrm{W}}\right)$ and by superposition $\left(K^{\mathrm{P}}\right)$ are shown in Figs. 3 to 6 , where the vertical, horizontal, rocking and cross-coupled horizontalrocking modes, respectively, are depicted. Different trends can be observed for each oscillation mode. Parameters $s / d$ and $n$ appear to govern the difference of vertical impedances, though pile-soil stiffness contrast and embedment ratio are also relevant. The difference decreases for narrowly spaced large pile groups, high relative pile-soil stiffness and high embedment ratios. As for the horizontal mode, $\chi$ and $\Delta \Theta$ are practically independent of $n$ for $\mathrm{a}_{0}<0.2$ and, in general, decrease for narrowly spaced piles and high embedment ratios. On the other hand, the embedment ratio governs the difference of rocking impedances, which decreases with increasing $D / B$, though it can be seen that the difference is smaller for small size pile groups. In this case, $\Delta \Theta$ is generally smaller than $5^{\circ}$, which, from a practical viewpoint, can be deemed negligible. It is also observed that the difference in the coupling term is independent of $n$ and is not significant for highly spaced pile groups and high embedment ratios, and that a greater variability in the results exists compared to the other impedance functions. Note that $\Delta \Theta$ tends to $180^{\circ}$ as $a_{0}$ goes to zero in some cases, being this due to the fact that $K^{\mathrm{W}}{ }_{\Phi \mathrm{x}}$ and $K^{\mathrm{P}}{ }_{\Phi \mathrm{x}}$ have opposite signs for static conditions.

The decrease in $\chi$ with an increase in embedment is a common trend to all oscillation modes. It can also be seen that, in the range of frequencies analyzed, the relationship between the impedance functions of the piled embedded footings as a whole and the impedances obtained by superposition is rather independent of $n$ for closely arranged pile groups $(s / d=2)$. Another interesting observation is the increase 
of $\chi$ and $\Delta \Theta$ at frequencies for which the group effect makes the pile foundation stiffer, reason why no significant peaks can be observed in the $s / d=2$ curves. This is due to the fact that the interaction between both types of foundation reduces the contribution of the pile group at such frequencies when analyzing the system as a whole. On the other hand, $\Delta \Theta$ is always negative in the vertical and horizontal modes at low frequencies, which suggests a higher damping capacity of the pile-reinforced footing than that estimated by superposition. Approximate estimates of $\Delta \Theta$ for the vertical, horizontal and rocking modes can be obtained from the regression formulas of Table 1.

Table 1. Approximate expressions for $\Delta \Theta\left(^{\circ}\right)$

\begin{tabular}{ccc}
\hline Rocking & & 0 \\
\hline Horizontal & & $197 a_{\mathrm{o}}^{2}-75 a_{\mathrm{o}}-0.06$ \\
\hline Vertical & $2 \times 2$ & $(s / d)^{0.62} 215 a_{\mathrm{o}}^{2}-(s / d)^{0.17} 58 a_{\mathrm{o}}$ \\
\cline { 2 - 3 } & $3 \times 3$ & $446 a_{\mathrm{o}}{ }^{2}-111 a_{\mathrm{o}}-0.3$ \\
\hline
\end{tabular}

\section{Kinematic Interaction Factors}

Moduli of translational and rotational kinematic response functions $I_{U}$ and $I_{\Phi}$, respectively, of $2 \times 2$ and $3 \times 3$ piled embedded footings, pile groups and embedded footings under vertically-incident plane shear waves are shown in Figs. 7 and 8 for $s / d$ $=2$ and 5, respectively. Both factors are measured at pile cap level (point $A$ in Fig 1) and are normalized with the free-field motion at the surface, $u_{f f}$, both being functions of the dimensionless frequency ratio $a_{\mathrm{o}}=\omega d / c_{\mathrm{s}}$ (Blaney et al. 1976)

$$
\begin{aligned}
& \mathrm{I}_{\mathrm{U}}=\mathrm{I}_{\mathrm{U}}\left(\alpha_{0}\right) \equiv \frac{\mathrm{u}_{\mathrm{A}}}{\mathrm{u}_{\mathrm{ff}}} \\
& \mathrm{I}_{\Phi}=\mathrm{I}_{\Phi}\left(\alpha_{0}\right) \equiv \frac{\theta_{\mathrm{A}} B}{\mathrm{u}_{\mathrm{ff}}},
\end{aligned}
$$

The dependence of dimensionless frequency to pile diameter is noteworthy, as kinematic response functions for footings are usually plotted with a dimensionless frequency proportional to the width of the footing (i.e. $a^{\prime}{ }_{o}=\omega B / c_{\mathrm{s}}$ ). In this case, the change in scale is linear as $B / d=(s / d) \cdot(n / 2)$, which can be used to interpret the results in an alternative way.

As it is well known, pile foundations, embedded in soils whose mechanical properties are relatively constant all through the length of the piles, do not filter out the seismic input signal for a large range of frequencies which depends on the pilesoil stiffness contrast $E_{\mathrm{p}} / E_{\mathrm{s}}$. However, the fact that the use of piled embedded footings entails a significant filtering of the seismic signal starting at relatively low frequencies is an interesting observation for the conceptual design of structures for earthquake resistance, being a drawback the generation of ample rotations.

Both the translational and rotational kinematic interaction factors are basically independent of $n$ though, obviously, differences can be observed. For amply spaced 
groups $(s / d=5$, Fig 8$)$, the embedded footing response is an excellent approximation of the piled footing response. On the other hand, for closely spaced groups $(s / d=2$, Fig 7), the approximation is not so accurate, being slightly conservative for the translational case, but un-conservative for the rotational one, a feature which should be recognized when analyzing tall and stiff structures, such as bridge piers, for which the rotational behaviour of the foundation is important.

\section{Conclusions}

Time-harmonic elastodynamic analyses of piled embedded footings were presented to provide insight into the behaviour of this type of foundations in relation to the response of their individual components (embedded footings and pile groups) analyzed separately. To this end, a rigorous three-dimensional frequency-domain boundary-element numerical scheme, coupled with a finite-element technique for the pile elements, was employed. First, a set of 10 dimensionless ratios was derived to describe the problem by means of Buckingham's theorem of dimensional analysis. Secondly, dimensionless plots were computed referring to 336 parameter combinations, for dynamic stiffness functions in vertical, horizontal and rocking modes, and kinematic response coefficients to vertically propagating $\mathrm{S}$ waves.

The impedance obtained by superposition of pile group and footing stiffness functions is generally higher than that arising from the analysis of the system as a single problem. This difference can be attributed to interaction phenomena between the pile group and the embedded footing, which are neglected in the superposition approach. More precisely, vertical, horizontal, rocking and cross-coupled terms can be up to $100 \%, 50 \%, 20 \%$ and $20 \%$ higher, respectively, though differences decrease rapidly with frequency. On the other hand, phase differences are normally below $20^{\circ}$ and denote that the damping capacity of the system acting as a whole is greater than that estimated from the superposition. This effect is particularly apparent in the vertical and horizontal modes at low frequencies. Besides, the dependence of the response to parameters such as pile-to-pile separation, pile-soil stiffness ratio was elucidated. The effect of embedment was shown to be particularly important, for it was observed that the higher the embedment, the less the difference between rigorous and superposition-based estimates. This trend is anticipated, given the omission of embedment effects in the assessment of pile group impedance.

Overall, the superposition approach was found to be sound as an engineering tool to address the problem at hand, provided that those functions with largest errors are identified and corrected. To do so, a set of dimensionless graphs and simple expressions are provided. Following this procedure, it is possible to estimate, with engineering accuracy, the dynamic stiffness and damping functions of piled embedded footings, assuming that those of embedded footings and pile groups, separately, are obtained by other available procedures.

Under kinematic loading, piled embedded footings were found to be less compliant to soil movement than their parts analyzed separately. Translational kinematic response factors decrease faster with frequency than those corresponding to pile groups or footings alone, while rotational kinematic interaction factors were found to increase more rapidly. Overall, kinematic response of embedded footings was found to provide suitable estimates of the piled embedded footing's behaviour. 


\section{Acknowledgments}

This work was partially supported by the Ministry of Education and Science of Spain through research project BIA2007-67612-C02-01, co-financed by the European Fund of Regional Development. The second Author is indebted to Professor Jonathan P. Stewart, University of California at Los Angeles, for fruitful discussions on the topic.

\section{References}

Ahmad S. and Banerjee P.K, (1988) 'Multi-domain BEM for two-dimensional problems of elastodynamics', International journal for numerical methods in engineering, 26(4), pp 891-911.

Akinmusuru J.O. (1980) 'Interaction of Piles and Cap in Piled Footings', J. Geotech. Eng. Div., Am. Soc. Civ. Eng., 106(11), 1263-1268.

Bentley K.J., El Naggar M.H. (2000) 'Numerical analysis of kinematic response of single piles', Can. Geotech. J. 37(6): 1368-1382.

Beskos D.E. (1997). 'Boundary element methods in dynamic analysis: Part II (19861996)', Appl. Mech. Rev., ASME, 50, 149-197.

Blaney G.W., Kausel E. and Roesset J.M. (1976) 'Dynamic stiffness of piles', Proc. $2^{\text {nd }}$ int. conf. num. methods geomech. Virginia Polytech. Inst. \& State Un. Blacksburg VA II, pp. 1010-1012.

Boulanger R.W., Curras C.J., Kutter B.L., Wilson D.W. and Abghari, A. (1999), 'Seismic Soil-Pile-Structure Interaction Experiments and Analyses', Journal of Geotechnical and Geoenvironmental Engineering, 125(9): 750-759.

Buckingham E. (1914) 'On physically similar systems: illustration of the use of dimensional equations', Phys. Rev., 4, 345-376.

Butterfield R. and Banerjee P.K. (1971) 'The problem of pile group-pile cap interaction', Geotechnique, 21(6), pp. 135-142.

Chow Y.K. and Teh C.I. (1991). 'Pile-cap-pile-group interaction in nonhomogeneous soil', J. Geotech. Eng., Am. Soc. Civ. Eng., 117(11), 1655-1668.

Combarieu O. and Evrard H. (1979). 'Combination Footing-Pile Foundations', Bulletin de Liaison del Laboratoires des Ponts et Chausses, 102, 49-58.

Combarieu O. and Morbois A. (1982). 'Combined footing-pile foundations', Annales de l'Institut technique du batiment et des travaux publics, 410, 1-34

Cooke R.W. (1986), 'Piled raft foundations on stiff clays - a contribution to design philosophy', Géotechnique, 36(2), 169-203.

Dobry R., Vicenti E., O'Rourke M.J. and Roesset J.M. (1982), 'Horizontal stiffness and damping of single piles', J. Geotech. Eng. Div. ASCE, 108(3), 439-459.

Dobry R. and Gazetas G. (1988). 'Simple method for dynamic stiffness and damping of floating pile groups', Géotechnique, 38, 557-574.

Domínguez J. (1993). 'Boundary elements in dynamics', Southampton, New York: Computational Mechanics Publications \& Elsevier Applied Science.

Fan K., Gazetas G., Kaynia A., Kausel E. and Ahmad. S. (1991). 'Kinematic seismic response of single piles and pile groups', J. Geotech. Eng., Am. Soc. Civ. Eng., 117(12), 1860-1879.

Gazetas G., Fan K., Kaynia A. and Kausel E. (1991). 'Dynamic interaction factors for floating pile groups', J. Geotech. Eng. Div., Am. Soc. Civ. Eng., 117(10), 1531-1548. 
Gazetas G. and Mylonakis G. (1998). 'Seismic soil-structure interaction: new evidence and emerging issues', emerging issues paper. Geotechnical Special Publication ASCE (75):1119-74.

Ishihara K., Cubrinovski M. (2004) Performance of piles as evaluated by three-layer model Geotechnical Special Publication ASCE (126): 167-191.

Karabalis D.L. and Beskos D.E. (1986). 'Dynamic response of 3-D embedded foundations by the boundary element method', Computer Methods in Applied Mechanics and Engineering, 56(1), pp. 91-119.

Kaynia A.M. (1982). 'Dynamic stiffness and seismic response of pile groups', Research Report R83-03, Massachusetts Institute of Technology, Cambridge, MA.

Mamoon S.M. and Banerjee P.K. (1990). 'Response of piles and pile groups to travelling SH-waves', Earthquake Eng. Struct. Dyn., 19(4), 597-610.

Miura K., Kaynia A.M., Masuda K., Kitamura E., and Seto Y. (1994). 'Dynamic behaviour of pile foundations in homogeneous and non-homogeneous media', Earthquake Eng. Struct. Dyn., 23(2), 183-192.

Mylonakis G., Nikolaou S., and Gazetas G. (2006). 'Footings under seismic loading: Analysis and design issues with emphasis on bridge foundations', Soil Dyn. Earthquake Eng., 26(9), 824-853.

Novak M. (1974), 'Dynamic stiffness and damping of piles', Can. Geotech. J., 11(4), 574-598.

Novak M. (1991), 'Piles under dynamic loads', $2^{\text {nd }}$ Int. Conf. Recent Adv. Geotech. Earthquake Eng. Soil Dyn., St Louis, Missouri, 22(3), 250-273.

Padrón L.A., Aznárez J.J. and Maeso O. (2007). 'BEM-FEM coupling model for the dynamic analysis of piles and pile groups', Eng. Anal. Boundary Elem., 31(6), 473-484.

Padrón L.A., Aznárez J.J. and Maeso O. (2008). 'Dynamic analysis of piled foundations in stratified soils by a BEM-FEM model', Soil Dyn. Earthquake Eng., 28, 333-346.

Padrón L.A., Mylonakis G. and Beskos D.E. (2009), 'Importance of footing-soil separation on dynamic stiffness of piled embedded footings', Int. J. for Num. Anal. Methods in Geomech.,33(11), pp. 1439-1448.

Pender M. (1993), 'Aseismic pile foundation design analysis', Bull. New Zealand national soc. Earthquake eng. 26(1), pp. 49-160.

Poulos H. (2001). 'Piled raft foundations: Design and applications', Geotechnique, 51(2), 95-113.

Randolph M.F. (1981). 'Response of flexible piles to lateral loading”, Geotechnique, 31(6), 247-259.

Reul O. and Randolph M.F. (2003). 'Piled rafts in overconsolidated clay: comparison of in situ measurements and numerical analyses', Geotechnique, 53(3), 301315.

Rollins K.M., Olsen R.J., Egbert J.J., Olsen K.G., Jensen D.H., and Garrett B.H. (2003). 'Response, analysis, and design of pile groups subjected to static and dynamic lateral loads', Report No. UT-03.03. Utah Department of Transportation Research and Development Division,

Stewart J.P. and Stewart A.F. (1997). 'Analysis of soil-structure interaction effects on building response from earthquake strong motion recordings at 58 sites', Report UCB/EERC-97/01, Earthquake engineering research center, University of California at Berkeley, CA. 


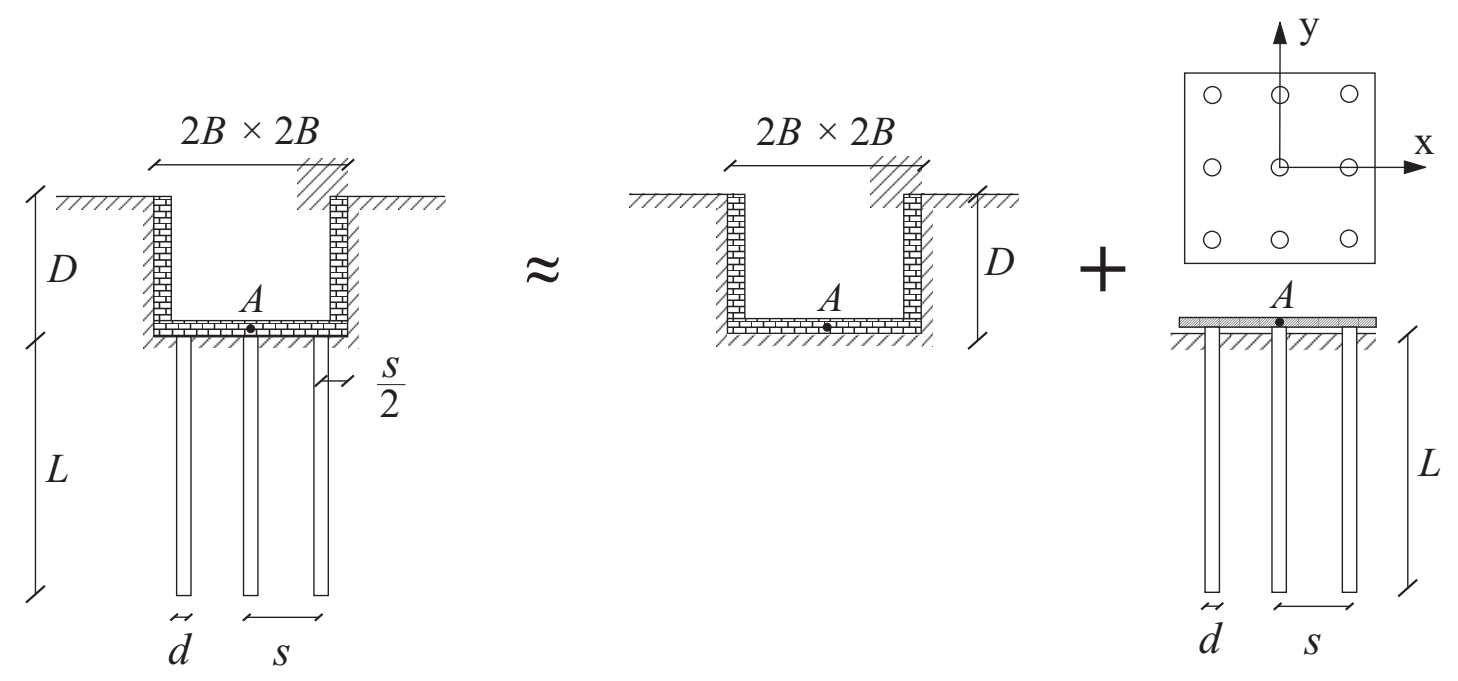

Figure 1: Problem statement and simple superposition approach.

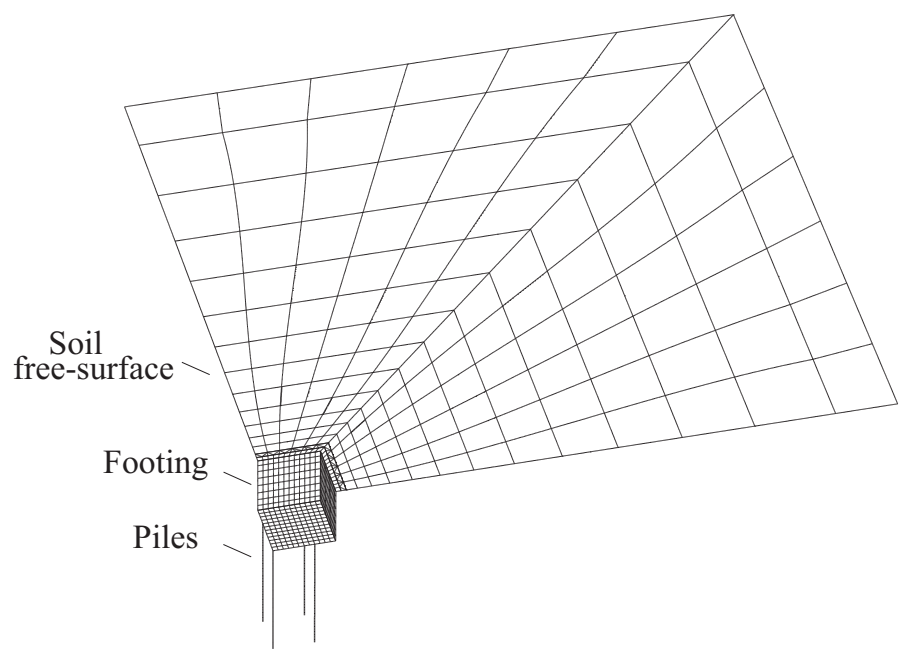

Figure 2: Discretization of one-quarter of an embedded footing on a $3 \times 3$ pile group. 

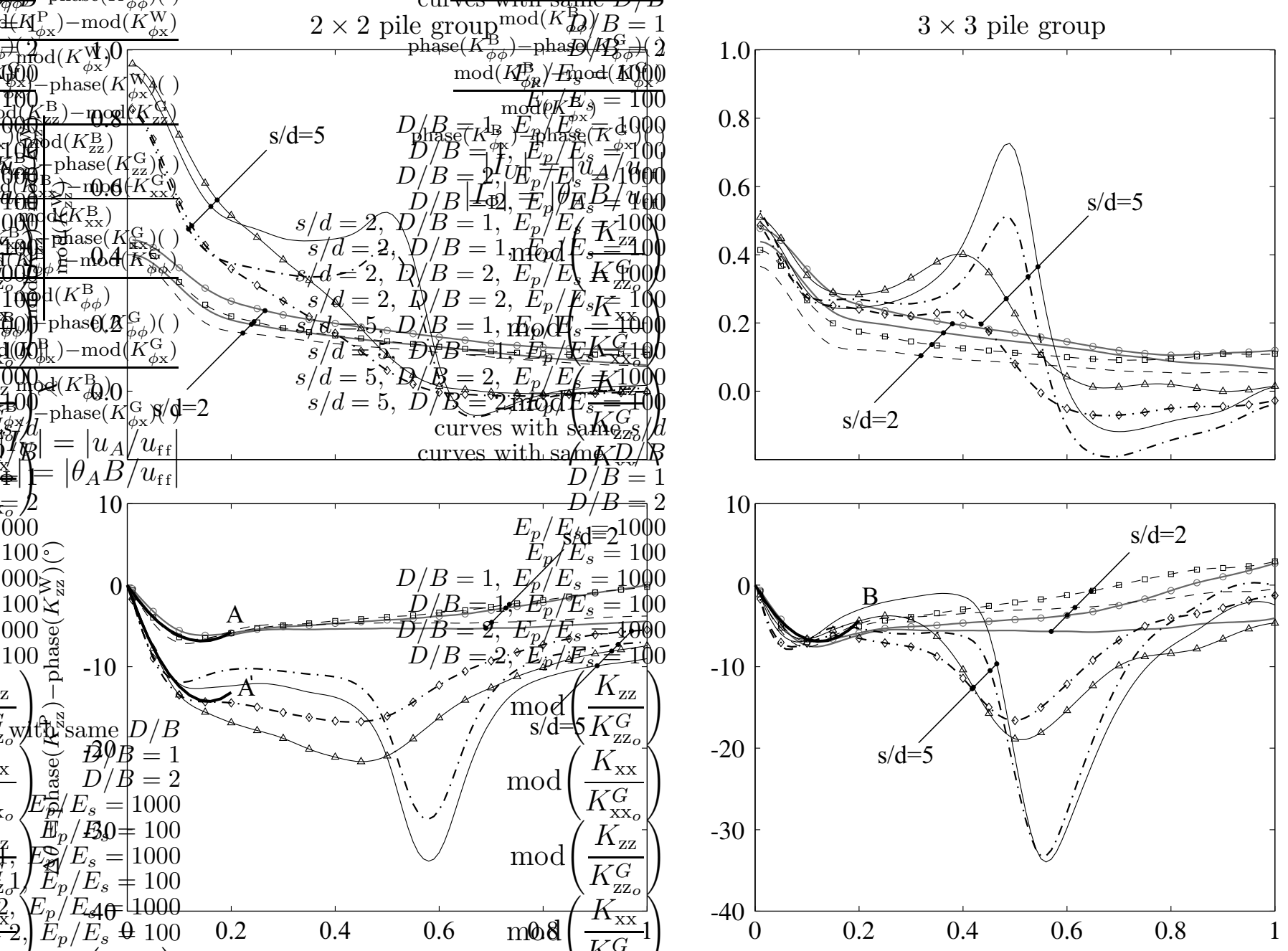

$$
a_{o}=\frac{\omega d}{c_{s}}
$$

$$
\begin{aligned}
& -s / d=2, D / B=1, E_{p} / E_{s}=1000-s / d=5, D / B=1, E_{p} / E_{s}=1000 \\
& \multimap s / d=2, D / B=1, E_{p} / E_{s}=100 \triangle \triangle s / d=5, D / B=1, E_{p} / E_{s}=100 \\
& -{ }_{-} s / d=2, D / B=2, E_{p} / E_{s}=1000 \cdots-\cdots s / d=5, D / B=2, E_{p} / E_{s}=1000 \\
& -\neg--s / d=2, D / B=2, E_{p} / E_{s}=100 \quad-\neg \cdot-s / d=5, D / B=2, E_{p} / E_{s}=100 \\
& \rightarrow \leftarrow \text { curves with same } s / d
\end{aligned}
$$

Figure 3: Comparison between modulus and phase of vertical impedances of embedded footings on piles, obtained rigorously, $K_{\mathrm{zz}}^{P}$ and by superposition $K_{\mathrm{zz}}^{W}$. 

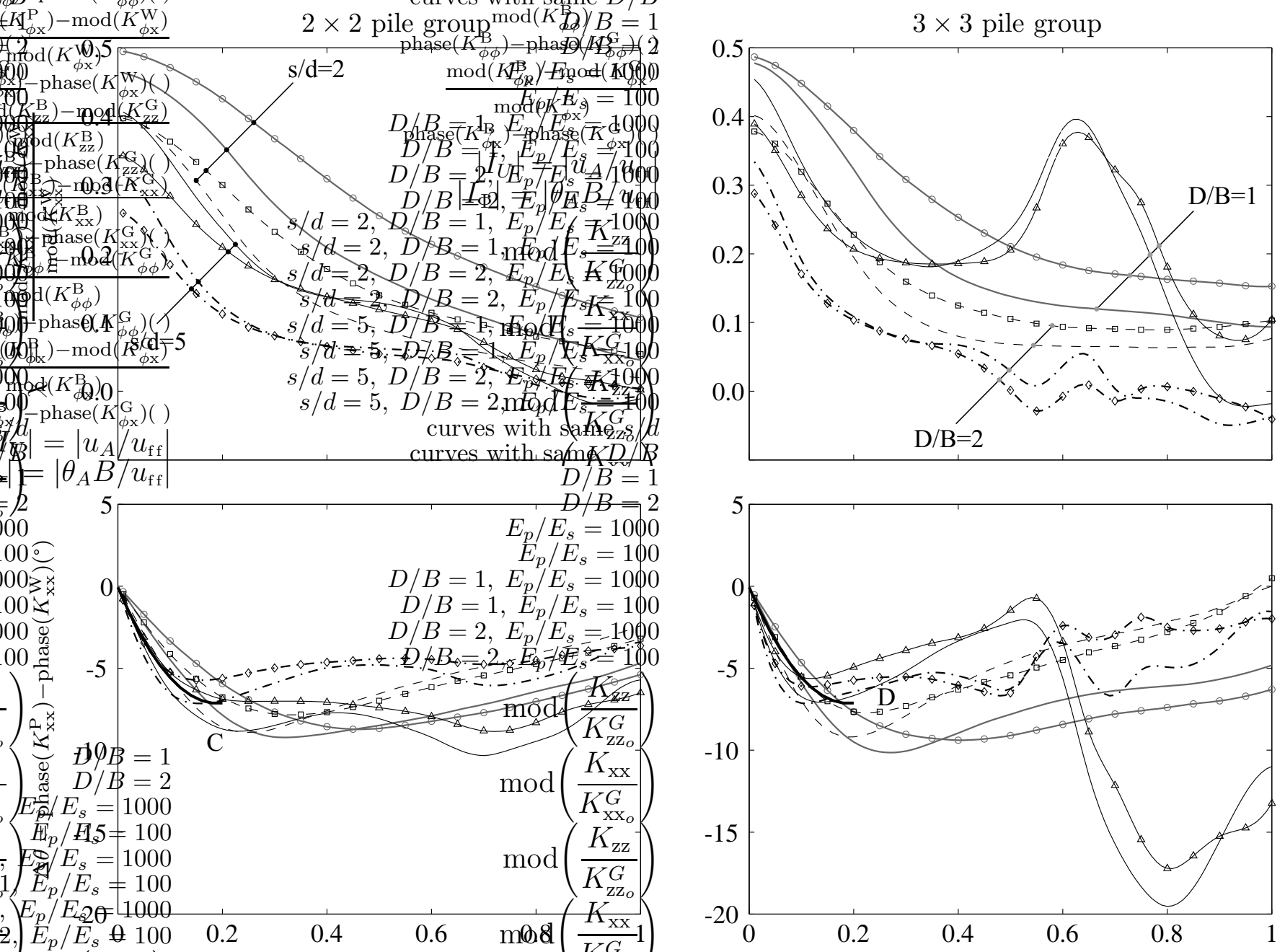

$$
a_{o}=\frac{\omega d}{c_{s}}
$$

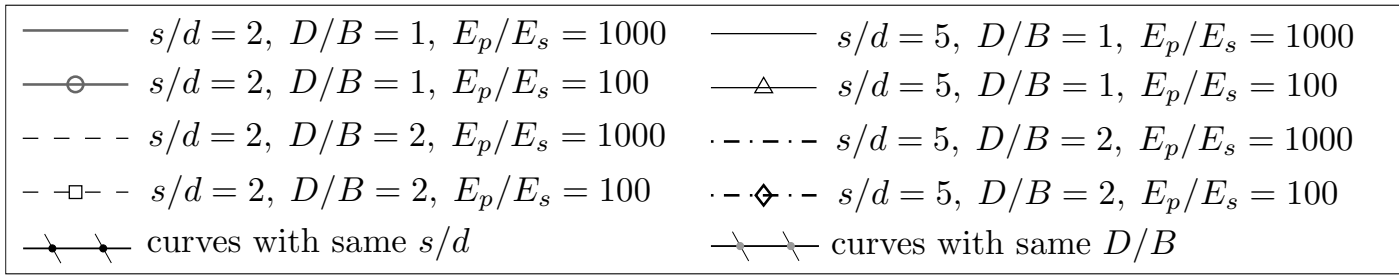

Figure 4: Comparison between modulus and phase of horizontal impedances of embedded footings on piles, obtained rigorously, $K_{\mathrm{xx}}^{P}$ and by superposition $K_{\mathrm{xx}}^{W}$. 

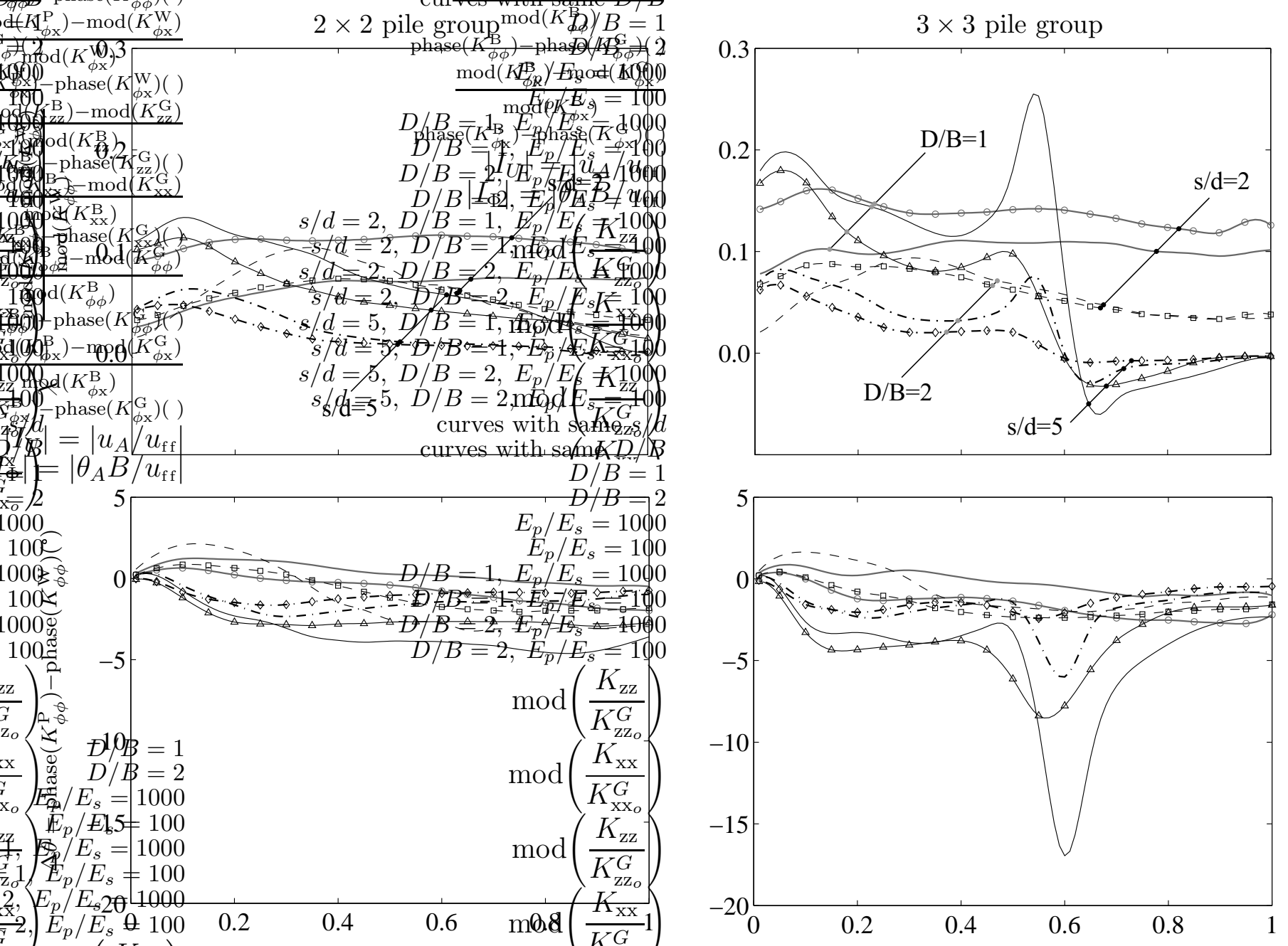

$$
a_{o}=\frac{\omega d}{c_{s}}
$$

\begin{tabular}{|c|c|}
\hline $\begin{aligned} \square & s / d=2, D / B=1, E_{p} / E_{s}=1000 \\
- & s / d=2, D / B=1, E_{p} / E_{s}=100 \\
---- & s / d=2, D / B=2, E_{p} / E_{s}=1000 \\
--\square-- & s / d=2, D / B=2, E_{p} / E_{s}=100 \\
\square- & \text { curves with same } s / d\end{aligned}$ & $\begin{array}{c}-s / d=5, D / B=1, E_{p} / E_{s}=1000 \\
\triangle \quad s / d=5, D / B=1, E_{p} / E_{s}=100 \\
-\bullet-s / d=5, D / B=2, E_{p} / E_{s}=1000 \\
-\diamond \cdot-s / d=5, D / B=2, E_{p} / E_{s}=100 \\
-\square \text { curves with same } D / B\end{array}$ \\
\hline
\end{tabular}

Figure 5: Comparison between modulus and phase of rocking impedances of embedded footings on piles, obtained rigorously, $K_{\phi \phi}^{P}$ and by superposition $K_{\phi \phi}^{W}$. 
$2 \times 2$ pile group
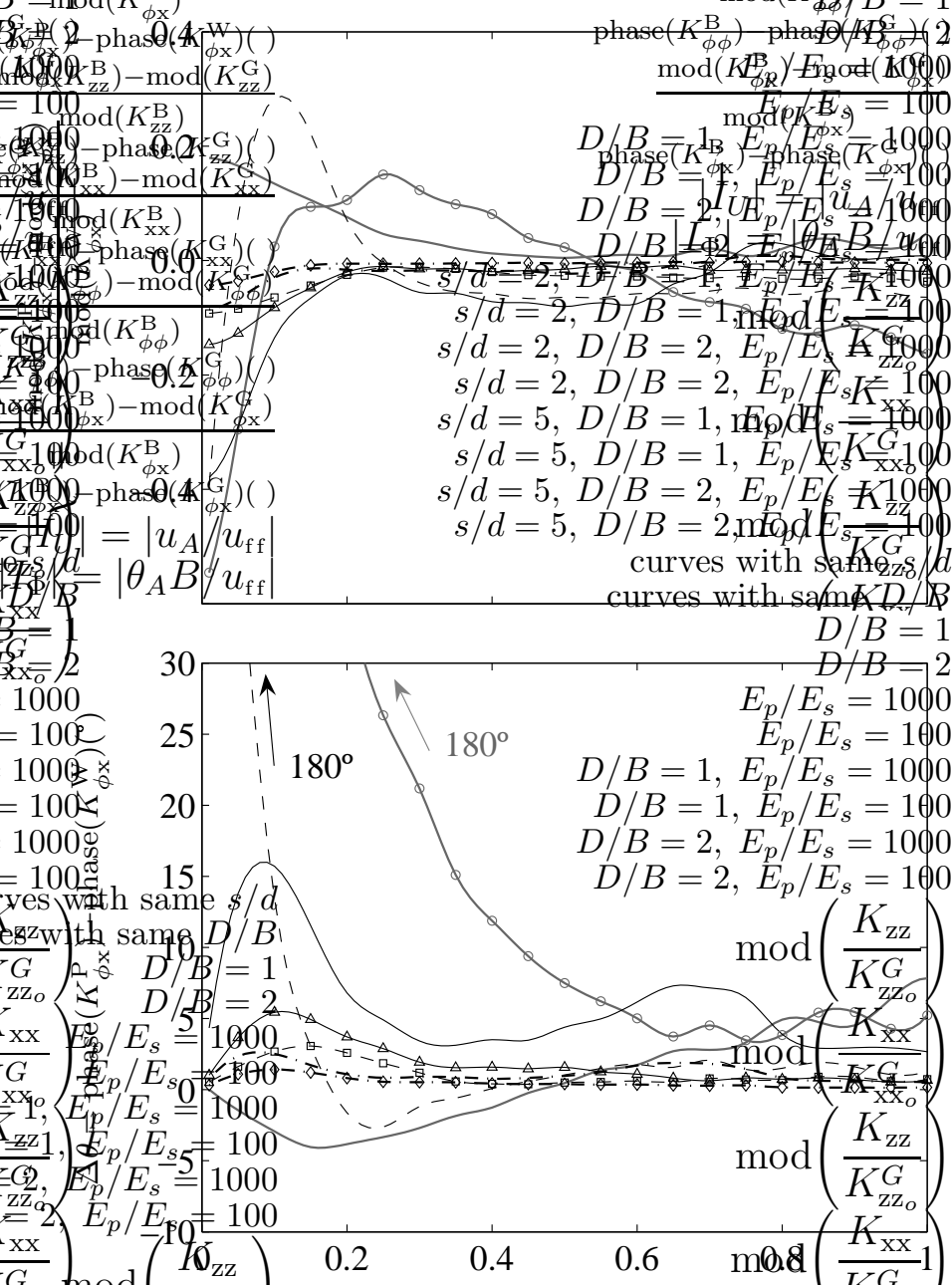

$3 \times 3$ pile group
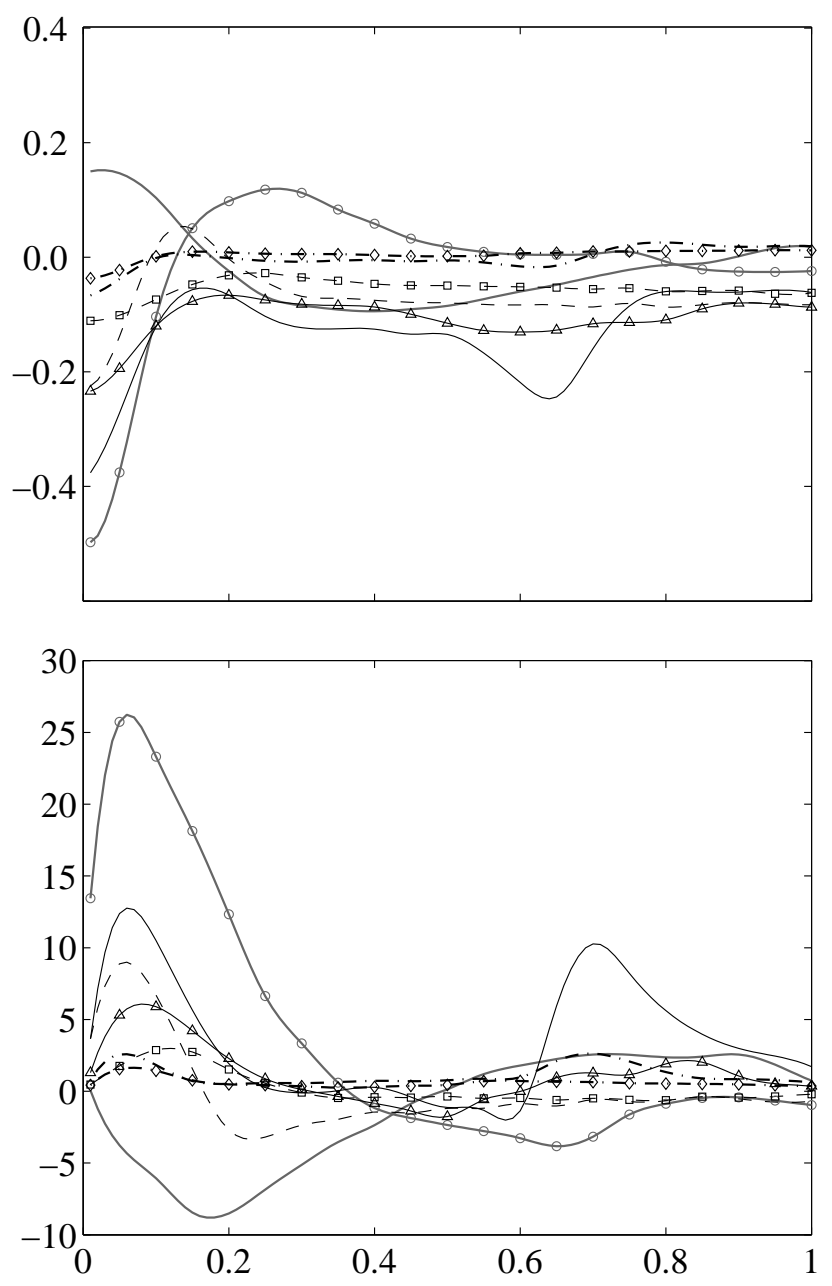

$a_{o}=\frac{\omega d}{c_{s}}$

$$
\begin{aligned}
& -s / d=2, D / B=1, E_{p} / E_{s}=1000 \longrightarrow s / d=5, D / B=1, E_{p} / E_{s}=1000 \\
& \multimap s / d=2, D / B=1, E_{p} / E_{s}=100 \quad \triangle \quad s / d=5, D / B=1, E_{p} / E_{s}=100 \\
& -{ }_{-} s / d=2, D / B=2, E_{p} / E_{s}=1000 \cdots-\cdots s / d=5, D / B=2, E_{p} / E_{s}=1000 \\
& --^{-}-s / d=2, D / B=2, E_{p} / E_{s}=100 \quad \cdot-\diamond \cdot-s / d=5, D / B=2, E_{p} / E_{s}=100
\end{aligned}
$$

Figure 6: Comparison between modulus and phase of cross-coupled horizontal-rocking impedances of embedded footings on piles, obtained rigorously, $K_{\phi \mathrm{x}}^{P}$ and by superposition $K_{\phi \mathrm{x}}^{W}$. 

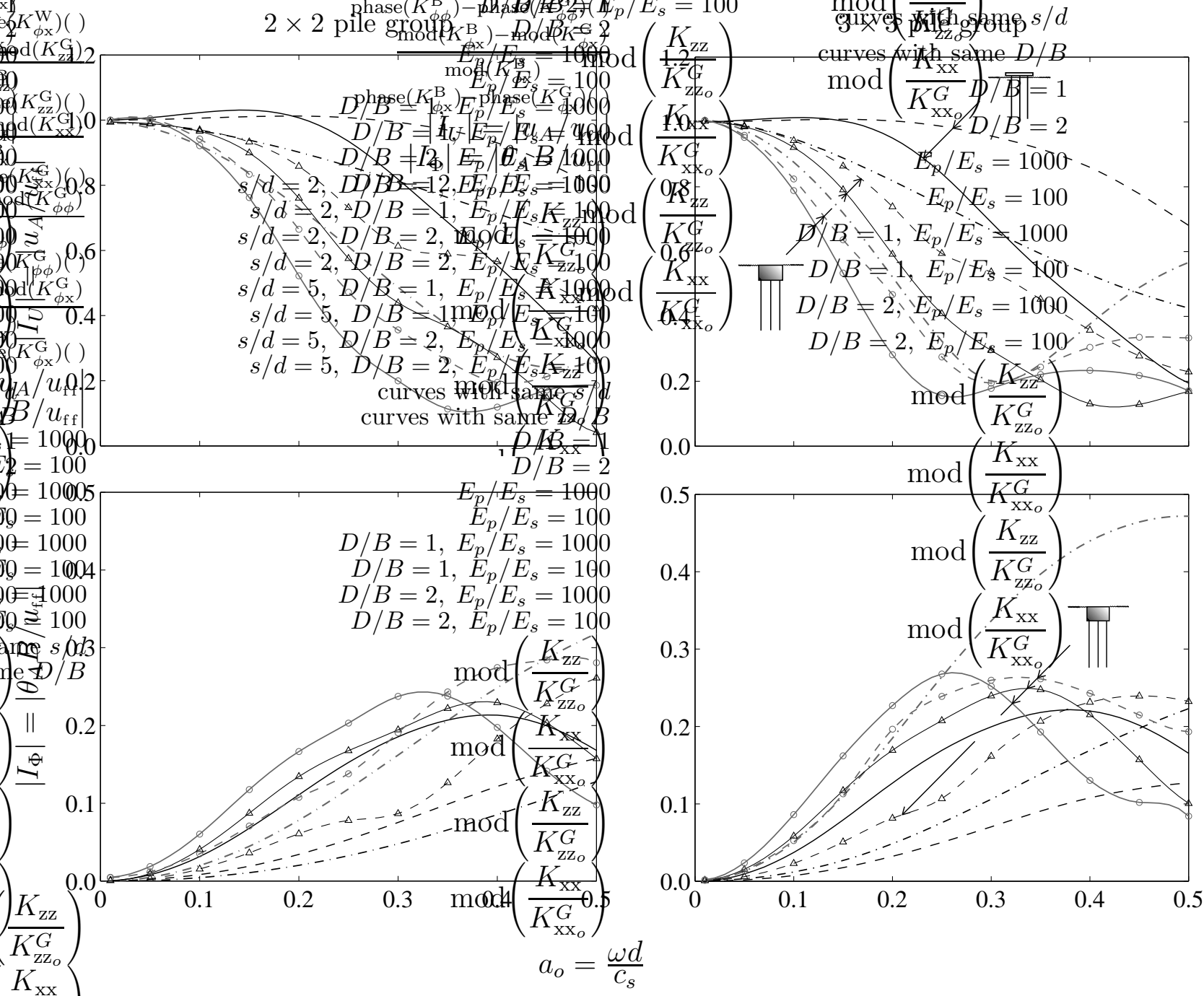

\begin{tabular}{|c|c|c|c|}
\hline $\begin{array}{ll}\cdots \cdots+\cdot & D / B=1 \\
\cdots \cdots- & D / B=2 \\
- & E_{p} / E_{s}=1000 \\
---- & E_{p} / E_{s}=100\end{array}$ & $\begin{array}{l}-\square \\
-\bar{\pi}\end{array}$ & $\begin{array}{l}\Delta \\
--\Delta- \\
0 \\
--a-\end{array}$ & $\begin{array}{l}D / B=1, E_{p} / E_{s}=1000 \\
D / B=1, E_{p} / E_{s}=100 \\
D / B=2, E_{p} / E_{s}=1000 \\
D / B=2, E_{p} / E_{s}=100\end{array}$ \\
\hline
\end{tabular}

Figure 7: Moduli of translational and rotational kinematic interaction factors for embedded footings, pile groups and embedded footings on pile groups under vertically incident $\mathrm{SH}$ waves. $s / d=2$. 

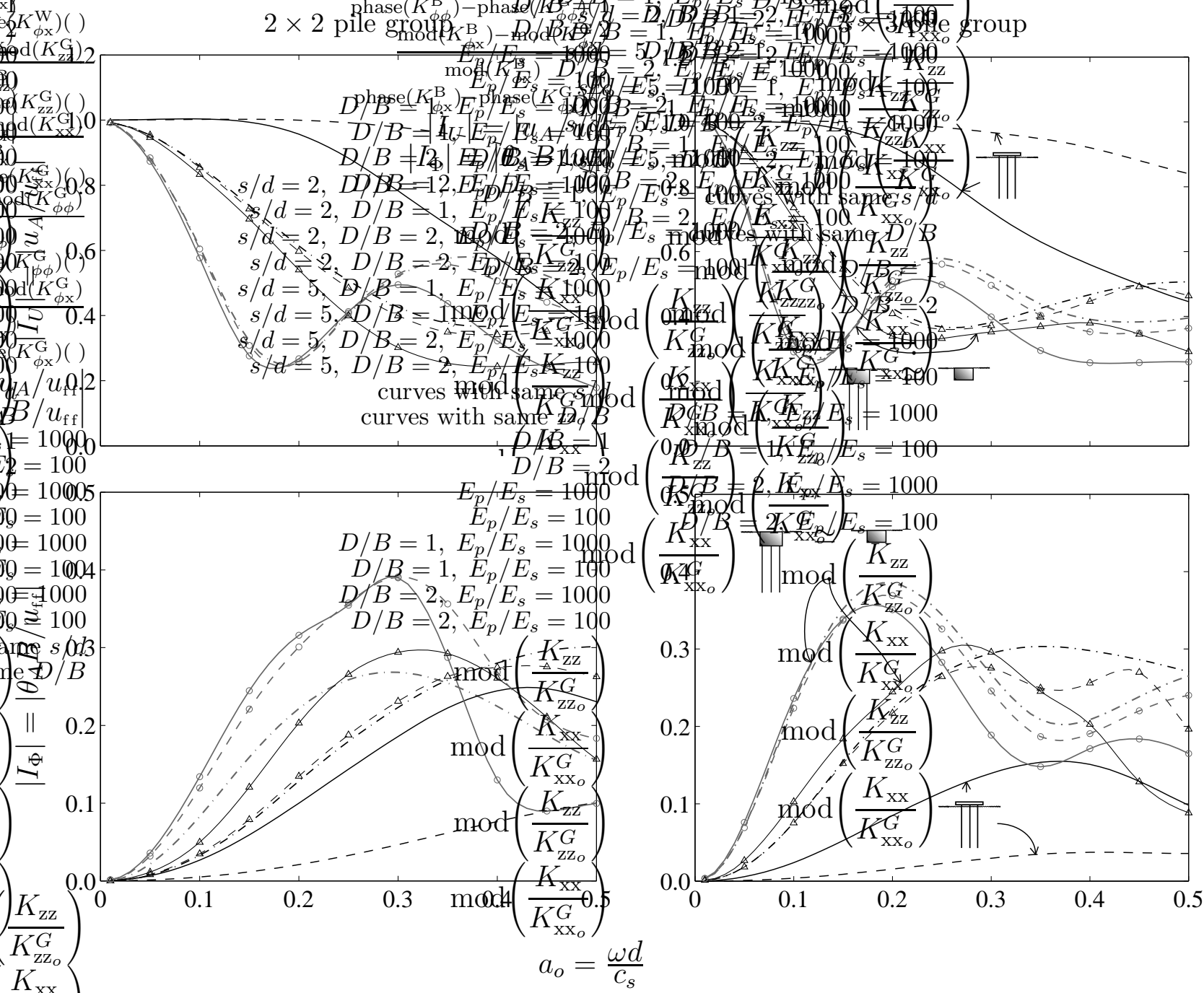

\begin{tabular}{|c|c|c|c|}
\hline $\begin{array}{ll}\cdots \cdots+ & D / B=1 \\
\cdots \cdots- & D / B=2 \\
& E_{p} / E_{s}=1000 \\
---- & E_{p} / E_{s}=100\end{array}$ & $\begin{array}{l}-\square \\
-\overline{T ा T}\end{array}$ & $\begin{array}{c}\Delta \\
--\Delta- \\
0 \\
--a-\end{array}$ & $\begin{array}{l}D / B=1, E_{p} / E_{s}=1000 \\
D / B=1, E_{p} / E_{s}=100 \\
D / B=2, E_{p} / E_{s}=1000 \\
D / B=2, E_{p} / E_{s}=100\end{array}$ \\
\hline
\end{tabular}

Figure 8: Moduli of translational and rotational kinematic interaction factors for embedded footings, pile groups and embedded footings on pile groups under vertically incident $\mathrm{SH}$ waves. $s / d=5$. 